\title{
Anthós
}

4-2010

\section{Weblogs as Autobiographical Discourse}

Matthew Bellinger

Portland State University

Follow this and additional works at: https://pdxscholar.library.pdx.edu/anthos

Part of the Nonfiction Commons

Let us know how access to this document benefits you.

\section{Recommended Citation}

Bellinger, Matthew (2010) "Weblogs as Autobiographical Discourse," Anthós: Vol. 2: Iss. 1, Article 2. https://doi.org/10.15760/anthos.2010.19

This open access Article is distributed under the terms of the Creative Commons Attribution-NonCommercialShareAlike 4.0 International License (CC BY-NC-SA 4.0). All documents in PDXScholar should meet accessibility standards. If we can make this document more accessible to you, contact our team. 
Matthew Bellinger

11 August 2009

\section{Weblogs as Autobiographical Discourse}

In this essay, I wish to pursue an - admittedly all too brief - inspection of the weblog as a form of autobiographical discourse. In essence, I want to ask the question, "How does the blog as a medium shape a particular kind of self-representation?" To accomplish this, I will first provide a working definition of the autobiographical blog. Next, I will examine two elements that I believe are key to the blog as a form of discourse; that is, the blog's temporal logic and its unique author-reader relationship. To conclude, I will argue that the aforementioned elements mark the blog as a new, distinct type of autobiographical discourse.

The first problem one encounters when attempting an analysis of the blog is one of definition: how to define the blog? This question, in and of itself, could easily swell to the size of a doctoral dissertation - if not larger. For the purposes of my project, however, I find it sufficient to let my subject matter do the definition. If it claims to be a blog, I'll call it a blog. This allows me to lay aside problematic forms of discourse, such as a regularly updated "News" section of a company website (it may have discrete entries, but is it a blog?) Furthermore, since my study is limited to self-representation within the blog form, I've consequently constrained my examination to blogs that are autobiographical in nature; that is, those that purport to disclose information about a single author. This stands in contrast to group blogs (since, no matter how personal the disclosure, such 
blogs have multiple authors), blogs maintained by and for organizations rather than individuals (i.e. political blogs lacking a specifically acknowledged author), and purely commercial blogs (those that exist solely for advertising - rather than a person advertising products).

With such a working definition and delineation of the autobiographical blog solidified, it is possible to move into the analysis of the medium itself. Now, at first glance it seems that there is little that separates the blog from the diary form. Could not the blog be, in a sense, the diary form turned digital? Like the diary, the blog consists of discrete entries. Like the diary, the blog has a beginning, but no distinct "end" in a narratological sense. Rather, there is simply a point at which the diary stops - the last entry. (Of course, such a narratological end can be incorporated into the diary or blog, but it is not a necessary component of either form.) However, these similarities between the diary and the blog are, at best, superficial. The temporal logic of the blog is of a completely different nature than that of the diary. Although the blog, like the diary, has no "end," the diary has a final point at which the author must stop writing in order for the diary to be published, get into the hands of the reader, etc. On the contrary, the blog has no such stopping point; it is constantly updated. The reader examines the blog as it is being created.

In this sense, the blog is both perpetually "unfinished" and perpetually "complete." It is unfinished in the sense that it is always possible for the author to add to the blog or edit previous posts. The blog is never final - never a "last word." The blog is perpetually complete in the sense that, due to its perpetually unfinished state, it must be regarded as an accurate reflection of the author's self-state at the present. Even if the 
author has not yet written all that he or she intends, this very incompleteness indicates something about the identity of the author - that they are prevented from creating additional posts, or that they refuse to. In this way, unlike the diary or the autobiography or the memoir, the blog exists in the present.

Treatment of time aside, the blog also differs from the diary in terms of the relationship and connection between the author and the reader. With a diary, autobiography, memoir, or any other printed medium, the reader's involvement is always after the fact. Readers may respond to the author by creating their own text, but this response does not change the original text; even if the original text undergoes edition, the original still stands separate as the first edition. For blogs, on the other hand, the reader's involvement is central. The blog offers a unique possibility: response through “comments." Comments are snippets of text that are attached to, but structurally distinct and separate from, individual blog entries. Notably, the number of comments attached to each blog entry varies widely; some blog entries may be devoid of comments, while others may display long dialogues within the comments section.

The specific numerical presence of comments, however, is not of prime importance; rather, it is the function of comments within the blog that is key. As the example taken from Peter Rollins' blog shows, blog comments can and do influence the overall direction of the blog; some blog entries are actually created in response to intratextual discourse - that is, comments. (It is also important to note that full blog entries are not the only way the author can respond to comments; it is not unusual for the author to leave their own comments.) This shows that the line between posts and comments is very 
permeable. The author influences the reader (eliciting a response), but the reader also influences the author (in terms of the direction of the blog entries proper).

This relationship of reciprocal influence is particularly important to understanding the blog as a medium, because it means that the author must always be writing with the possibility of near-instantaneous feedback from the reader. Even if readerly comments never actually appear, the author is faced with their potential appearance. The end result is a sort of paranoid discourse - a discourse self-aware of its own hyper-visibility and consequently, its directional instability. Furthermore, because of the aforementioned temporal logic of the blog (its existence in the present), this sense of paranoia must be understood as occurring at the moment of iteration. It is not that the author is writing and creating and identity first and then experiencing a paranoia that influences some sort of editorial move or amendment; rather, the paranoia is part and parcel of the original textual composition, to the degree that the author can be understood to be writing in response to as-of-yet-inexistent comments - precisely in an effort to maintain control of their own discourse. Blogging, then, is a sort of preemptive discourse.

This has further implications for self-representation within the blog, and further distinguishes the blog from other forms of autobiographical discourse. Since the blog is created in this paranoid, preemptive manner, each blog, as a textual artifact, can only be understood with respect to the reader's knowledge. In the diary, individual entries can be thought of as distinct, because they are a reflection of a single source - the lived experience of one person. In contrast, the blog stands as the fruit of both authorial and readerly discourse, and as a consequence, blog entries do not necessarily reflect the lived experience of a single person. That is to say, even if one had a perfect knowledge of the 
blog author's life outside of the blog, individual blog entries still may not make sense, because their meaning is developed by an author-reader interaction, rather than an author-experience reflection.

Thus, individual blog posts do not stand alone; they always reference the larger project of the blog as an entity. Interestingly, this means that the blog doesn't really start until the second post (e.g. the post that presupposes the blog's existence.) The first post must serve as an introductory post (and this is a seemingly universal necessity), to found the blog's existence and to establish the relationship between the author and the everpotentially-present reader.

But what does this say about the possibility of autobiography in the digital realm? The features of the blog form can - admittedly - be taken in many directions of interpretation, but in my mind, the blog represents a new kind of discourse - one that is both profoundly autobiographical and profoundly unlike more traditional forms of selfrepresentation. It is autobiographical precisely because of its temporal logic and authorreader relationship; the paranoia these two produce offers the chance for genuine disclosure, in that the constant pressure to respond forces the author to revert to quick, instinctual - rather than carefully shaped - writing. However, the blog is unlike traditional autobiographical discourse in that its autobiographical disclosure sharply separated from the author's intention. Disclosure doesn't happen on purpose; it happens because the reader goads the author into it. 


\section{Weblogs Cited}

Rollins, Peter. "Reading groups in key theological figures: Slavoj Žižek."

Peterrollins.net. Weblog. 30 July 2009. <http://peterrollins.net/blog/?p=261>

Rollins, Peter. “Is Slavoj Žižek even a theologian?” Peterrollins.net. Weblog. 30 July 2009. $<$ http://peterrollins.net/blog/?p=262> 